\title{
Lithium overdosage and related tests
}

\author{
Paolo D. Pigatto', Bernardo Dell'Osso ${ }^{2,3}$ and Gianpaolo Guzzi ${ }^{4^{*}}$
}

\begin{abstract}
Lithium acts biochemically through the inositol depletion in brain cortex. At low doses, however, it is partly effective and/or ineffective, whereas in high concentrations is toxic. We would like to make one point about this review. In fact, in our view, the patient should be given a support to correct hypernatremia and even sodium levels should be tested serially - along with serum lithium concentrations — because high sodium levels reduce the rate of elimination of lithium. Lithium is mainly a neurotoxicant. Lithium-related central nervous system toxicity as well as the cardiovascular and thyroid changes are most likely due to the cations $\left(\mathrm{Na}_{2}{ }^{+}\right.$and $\left.\mathrm{K}^{+}\right)$competition.
\end{abstract}

Haussmann and colleagues (2015) provide a very useful review of lithium intoxication. As they rightly point out, there is an urgent need for comprehensive evaluations in the clinical management of patients with lithium intoxication (Haussmann et al. 2015). Lithium, as lithium carbonate $\left(\mathrm{Li}_{2} \mathrm{CO}_{3}\right)$ and/or lithium citrate $\left(\mathrm{Li}_{2} \mathrm{C}_{6} \mathrm{H}_{5} \mathrm{O}_{7}\right)$, is among the most recommended drugs for the treatment of bipolar disorder by international guidelines (Casarett et al. 2008). Lithium acts biochemically through the inositol depletion in brain cortex (Casarett et al. 2008). At low doses, however, it is partly effective and/or ineffective, whereas in high concentrations is toxic (Casarett et al. 2008). Their study led the investigators to endorse a serial blood measurements of lithium (Haussmann et al. 2015) during the critical period of acute lithium poisoning (or acute-onchronic intoxication), mentioning previous studies to support such a position (Timmer and Sands 1999; Casarett et al. 2008). Therefore, the authors suggest that measurement of lithium (i.e., every 2-4 h) (Haussmann et al. 2015) should be incorporated in medical management in the emergency department. However, we would like to make one point about this review. In fact, in our view, the patient should be given a support to correct hypernatremia and even sodium levels should be tested seriallyalong with serum lithium concentrations-because high sodium levels reduce the rate of elimination of lithium (Liamis et al. 2009; Grunfeld and Rossier 2009). Lithium

\footnotetext{
*Correspondence: gianpaolo_guzzi@fastwebnet.it

${ }^{4}$ Italian Association for Metals and Biocompatibility Research-A.I.R.M.E.B., (not-for-profit organization), Via A. Banfi, 4, 20122 Milan, Italy

Full list of author information is available at the end of the article
}

is mainly a neurotoxicant (Casarett et al. 2008). Lithiumrelated central nervous system toxicity as well as the cardiovascular and thyroid changes are most likely due to the cations $\left(\mathrm{Na}_{2}{ }^{+}\right.$and $\left.\mathrm{K}^{+}\right)$competition (Casarett et al. 2008). As the authors correctly assert, (Haussmann et al. 2015) pharmacologic management, laboratory testing, and specific recommendation should be implemented to improve effectiveness of lithium poisoning treatment.

\section{Author details}

${ }^{1}$ Department of Biomedical, Surgical and Dental Sciences, Unit of Oral Pathology and Medicine, IRCCS Galeazzi Hospital, University of Milan, Milan, Italy. ${ }^{2}$ Fondazione IRCCS Ca' Granda Policlinico, Department of Pathophysiology and Transplant, University of Milan, Milan, Italy. ${ }^{3}$ Bipolar Disorders Clinic, Stanford Medical School, Palo Alto, CA, USA. ${ }^{4}$ Italian Association for Metals and Biocompatibility Research-A.I.R.M.E.B., (not-for-profit organization), Via A. Banfi, 4, 20122 Milan, Italy.

\section{Competing interests}

The authors declare that they have no competing interests.

Received: 14 December 2015 Accepted: 23 December 2015

Published online: 12 January 2016

\section{References}

Casarett LJ, Doull J, Klaassen CD. Casarett and Doull's toxicology: the basic science of poisons. 7th ed. New York: McGraw-Hill Medical; 2008.

Grunfeld JP, Rossier BC. Lithium nephrotoxicity revisited. Nat Rev Nephrol. 2009;5(5):270-6.

Haussmann R, Bauer M, von Bonin S, Grof P, Lewitzka U. Treatment of lithium intoxication: facing the need for evidence. Int J Bipolar Disord. 2015;3(1):23.

Liamis G, Milionis HJ, Elisaf M. A review of drug-induced hypernatraemia. NDT Plus. 2009;2(5):339-46.

Timmer RT, Sands JM. Lithium intoxication. J Am Soc Nephrol. 1999;10(3):666-74.

\section{Springer}

(c) 2016 Pigatto et al. This article is distributed under the terms of the Creative Commons Attribution 4.0 International License (http://creativecommons.org/licenses/by/4.0/), which permits unrestricted use, distribution, and reproduction in any medium, provided you give appropriate credit to the original author(s) and the source, provide a link to the Creative Commons license, and indicate if changes were made. 